\title{
Oomycete Species Associated with Soybean Seedlings in North America-Part II: Diversity and Ecology in Relation to Environmental and Edaphic Factors
}

\author{
J. Alejandro Rojas, Janette L. Jacobs, Stephanie Napieralski, Behirda Karaj, Carl A. Bradley, Thomas Chase, Paul D. Esker, \\ Loren J. Giesler, Doug J. Jardine, Dean K. Malvick, Samuel G. Markell, Berlin D. Nelson, Alison E. Robertson, John C. \\ Rupe, Damon L. Smith, Laura E. Sweets, Albert U. Tenuta, Kiersten A. Wise, and Martin I. Chilvers
}

First, second, third, fourth, and nineteenth authors: Department of Plant, Soil and Microbial Sciences, and first and nineteenth authors: Program in Ecology, Evolutionary Biology and Behavior, Michigan State University, East Lansing 48824; fifth author; Department of Crop Sciences, University of Illinois, Urbana 61801; sixth author: Department of Plant Science, South Dakota State University, Brookings 57007; seventh and fifteenth authors: Department of Plant Pathology, University of Wisconsin-Madison 53706; eighth author: Department of Plant Pathology, University of Nebraska-Lincoln 68583; ninth author: Department of Plant Pathology, Kansas State University, Manhattan 66506; tenth author: Department of Plant Pathology, University of Minnesota, St. Paul 55108; eleventh and twelfth authors: Department of Plant Pathology, North Dakota State University, Fargo 58105; thirteenth author: Department of Plant Pathology and Microbiology, Iowa State University, Ames 50011; fourteenth author: Department of Plant Pathology, University of Arkansas, Fayetteville 72701; sixteenth author: Division of Plant Sciences, University of Missouri, Columbia 65211; seventeenth author: Ontario Ministry of Agriculture, Food \& Rural Affairs, Ridgetown, ON N0P2C0, Canada; and eighteenth author: Department of Botany and Plant Pathology, Purdue University, West Lafayette, IN 47907.

Current address of C. A. Bradley: Department of Plant Pathology, University of Kentucky, Princeton 42445.

Current address of P. D. Esker: School of Agronomy, University of Costa Rica, San Jose, Costa Rica.

Accepted for publication 10 November 2016.

\begin{abstract}
Soybean (Glycine $\max (\mathrm{L}$.$) Merr.) is produced across a vast swath of North$ America, with the greatest concentration in the Midwest. Root rot diseases and damping-off are a major concern for production, and the primary causal agents include oomycetes and fungi. In this study, we focused on examination of oomycete species distribution in this soybean production system and how environmental and soil (edaphic) factors correlate with oomycete community composition at early plant growth stages. Using a culture-based approach, 3,418 oomycete isolates were collected from 11 major soybean-producing states and most were identified to genus and species using the internal transcribed spacer region of the ribosomal DNA. Pythium was the predominant genus isolated and investigated in this study. An ecology approach was taken to understand the diversity and distribution of oomycete species across geographical locations of soybean production. Metadata associated with field sample locations were collected using geographical information systems. Operational taxonomic units (OTU) were used in this study to investigate diversity by location, with OTU being defined as isolate sequences with $97 \%$ identity to one another. The mean number of OTU ranged from 2.5 to 14 per field at the state level. Most OTU in

this study, classified as Pythium clades, were present in each field in every state; however, major differences were observed in the relative abundance of each clade, which resulted in clustering of states in close proximity. Because there was similar community composition (presence or absence) but differences in OTU abundance by state, the ordination analysis did not show strong patterns of aggregation. Incorporation of 37 environmental and edaphic factors using vector-fitting and Mantel tests identified 15 factors that correlate with the community composition in this survey. Further investigation using redundancy analysis identified latitude, longitude, precipitation, and temperature as factors that contribute to the variability observed in community composition. Soil parameters such as clay content and electrical conductivity also affected distribution of oomycete species. The present study suggests that oomycete species composition across geographical locations of soybean production is affected by a combination of environmental and edaphic conditions. This knowledge provides the basis to understand the ecology and distribution of oomycete species, especially those able to cause diseases in soybean, providing cues to develop management strategies.
\end{abstract}

Soybean (Glycine max (L.) Merr.) is a major crop in North America, with a reported 85 million production acres in the United States yielding an estimated value of $\$ 40$ billion annually (American Soybean Association 2015). The prevalence of root rot diseases in soybean production in the United States and Ontario, Canada has resulted in increased production costs and reduced yields due to reduced plant stands, which can require replanting of entire fields. Soybean seed and seed treatments constitute $48 \%$ of the growers input cost, which represents a total cost of U.S.\$7.5 billion dollars annually (American Soybean Association 2015).

Corresponding author: M. I. Chilvers; E-mail address: chilvers@msu.edu

*The $\boldsymbol{e}$-Xtra logo stands for "electronic extra" and indicates that one supplementary table, three supplementary figures, and two supplementary files are published online.

(c) 2017 The American Phytopathological Society
Among the most common causes of soybean root rot diseases and damping-off are oomycete species, the most prevalent of which are members of the genera Pythium and Phytophthora (Broders et al. 2007; Dorrance et al. 2003). However, the extent of the oomycete community composition and species distribution associated with soybean roots are not well known in the United States. Successful disease management relies on a thorough understanding of the pathosystem. In this regard, there is a crucial need to characterize oomycete species distribution, community composition, and the role of biotic and abiotic factors in these communities.

The genus Pythium is typically linked with early-season diseases such as seedling root rot and damping-off, and multiple species have been often implicated (Zhang and Yang 2000; Zhang et al. 1998). Phytophthora sojae is also widely recognized as a major soybean pathogen causing root and stem rot (Tyler 2007). There has been an exponential increase in the reporting of new oomycete species in the last 20 years, as a result of the sequencing of genes, mainly internal 
transcribed spacer (ITS) of ribosomal DNA (rDNA) and cytochrome oxidase subunit I (Lévesque 2011). The use of these DNA markers has enabled the identification of new or overlooked causal agents of disease. Using these markers as tools, surveys of oomycete species composition and description of new species allows for a greater understanding of oomycete communities, including identification of pathogens, host ranges, and environmental conditions that influence the composition of species in pathogen communities.

The influence of environment on the diversity and distribution of plant pathogens is not a new concept. However, it is important to consider different approaches such as the use of ecological methods to gain a better understanding of pathosystems for improved disease management. Most of the studies on oomycete diversity have focused on the genus Phytophthora, due to the threat that it represents to natural and agricultural ecosystems (Hansen et al. 2012; Knaus et al. 2015; Nagel et al. 2015; Parke et al. 2014; Scibetta et al. 2012). Parke et al. (2014) studied the Phytophthora spp. community assembly in a landscape nursery setting to improve disease management by identifying critical points and practices that may increase species abundance of Phytophthora, hence increasing the risk for disease. The diversity of Phytophthora spp. was cataloged in different components of the production system, including irrigation water, potting mix, and the field environment. A critical production point identified was the soil and gravel, which served as the main source for Phytophthora spp., potentially increasing the introduction of pathogenic species into the nursery (Parke et al. 2014). This systematic approach provides a good example of the application of community-level analysis in improving disease management. Nelson and Karp (2013) utilized molecular techniques to study the diversity of oomycete species associated with the invasive grass species Phragmites australis (Cav.) Trin. ex Steudel (European common reed) and the related native species. The pathogenicity of these oomycetes isolates was evaluated by Crocker et al. (2015) on the invasive and native grass species. Addressing the interaction of host and oomycete community present in the soil, Crocker et al. (2015) found that Pythium spp. were abundant for both hosts but Pythium spp. associated with soil in locations invaded by Phragmites spp. had increased virulence compared with Pythium spp. isolated from soil surrounding only native species.

There have been recent studies focused on the distribution of oomycete species associated with soybean seedling diseases at an intrastate scale. Oomycete species were obtained by isolation from seedlings or by baiting from soil under controlled conditions. The isolates recovered were further characterized by evaluating for pathogenicity or fungicide resistance, thus providing a regional profile of the oomycete species distribution and their traits (Broders et al. 2007; Jiang et al. 2012; Marchand et al. 2014; ZitnickAnderson and Nelson 2015). To gain a more global understanding of oomycete diversity and community composition, the effect of abiotic factors must also be taken into consideration, because environmental conditions influence the distribution and abundance of species. It has been previously reported that soil (edaphic) properties such as $\mathrm{pH}$ of approximately 6 , low calcium concentration $(1.515 \mu \mathrm{g} / \mathrm{g})$, and low cation exchange capacity (CEC) (13.02 meq per $100 \mathrm{~g}$ ) were associated with species diversity in different Pythium communities in Ohio, resulting in reduced diversity and higher levels of disease incidence (Broders et al. 2009). ZitnickAnderson et al. (2014) reported significant models that associated CEC with specific Pythium spp. isolated from soybean fields in North Dakota: Pythium irregulare and P. heterothallicum were associated with increased CEC, while $P$. kashmirense was associated with decreased CEC. These findings reveal the complexity of the system and the need to implement ecological approaches to understand the distribution and diversity of oomycete species and the prevalence of pathogenic species.

In this study, we present a continental-scale study of oomycetes that infect soybean roots using a culture-based approach to gain insight into large-scale patterns of the diversity of these organisms. To identify environmental and edaphic factors, metadata were obtained from geographic coordinates at each sample site. By incorporating associated environmental data, we analyzed the correlation of temperature, soil chemical and physical properties, precipitation, and latitude, among others, with the oomycete community composition. We hypothesize that oomycetes species distribution is affected by regional edaphic and environmental conditions, and species are more likely to infect soybean plants under specific environmental conditions, such as cold temperatures and high soil moisture. The goals of the present study were to (i) establish community structure of oomycete species associated with soybean seedling diseases across soybeanproducing states in the United States and Ontario, Canada; (ii) explore the influence of different environmental and edaphic factors on oomycete community structure; and (iii) determine the prevalence and distribution of oomycete species responsible for seed and root rot diseases.

\section{MATERIALS AND METHODS}

Isolation, culture collection, and DNA extraction. A survey was conducted across 11 U.S. states and Ontario, Canada by the sampling of 64 and 61 fields in 2011 and 2012, respectively (Supplementary Fig. S1). Between four and seven fields were sampled per participating state by collaborators in each of those states, targeting fields with a history of seedling disease or plant stand issues. Collaborators followed a standard sampling procedure, where 50 symptomatic seedlings were collected from a W-shaped transect across each field. In some fields, there were an insufficient number of plants with aboveground symptoms to collect 50 symptomatic plants and, in those cases, seedlings were randomly sampled. Soil samples were taken from some Ontario fields and isolates were baited from soil using soybean seed; therefore, these samples were not included for analyses. Seedlings were transported in coolers and samples were processed within $24 \mathrm{~h}$ after collection (Rojas et al. in press). Plant processing and isolation were done as reported by Rojas et al. (in press). Briefly, seedlings were washed under running tap water, and $1-\mathrm{cm}$ root sections with characteristic discoloration associated with root infection were cut and placed onto a semiselective medium. In 2011, the semiselective medium was corn meal agar (CMA) amended with PARPB (pentachloronitrobenzene [PCNB] $50 \mathrm{mg} /$ liter, ampicillin $250 \mathrm{mg} /$ liter, rifampicin $10 \mathrm{mg} / \mathrm{liter}$, pimaricin $5 \mathrm{mg} / \mathrm{liter}$, and benomyl $10 \mathrm{mg} / \mathrm{liter}$ (Jeffers 1986). Due to the low number of Phytophthora spp. collected in 2011, both CMA-PARPB and V8 medium amended with RPBH (rifampicin $10 \mathrm{mg} / \mathrm{liter}$, PCNB $20 \mathrm{mg} / \mathrm{liter}$, benomyl $10 \mathrm{mg} / \mathrm{liter}$, and hymexazol $20 \mathrm{mg} / \mathrm{liter}$ ) were used in the second year of the survey in an attempt to improve the recovery of Phytophthora spp. (Dorrance et al. 2008; Jeffers 1986).

Culture plates were incubated for 7 days at $20^{\circ} \mathrm{C}$ and checked daily for hyphal growth and morphology consistent with oomycetes. Single pure cultures were obtained by hyphal tipping and transfer to fresh CMA-PARPB or V8-RPBH medium. Transfer of 5-mm plugs from fresh isolate cultures onto potato carrot agar slants and hemp seed vials were used for long-term storage (Erwin and Ribeiro 1996; van der Plaats-Niterink 1981). In addition, three to five 5-mm plugs from fresh cultures were placed into $50 \mathrm{ml}$ of a $10 \%$ V8 broth amended with ampicillin (100 mg/liter) and incubated for 7 to 10 days at room temperature without agitation. Oomycete mycelia were harvested from broth cultures, lyophilized overnight, and ground for DNA extraction. DNA extraction was achieved by adding $100 \mathrm{mg}$ of ground mycelia and $800 \mu \mathrm{l}$ of cetyltrimethylammonium bromide lysis buffer into sterile AutoGen tube racks (AutoGen AGPR-S-STAR; AutoGen AG00121; AutoGen Inc., Holliston, MA) and incubated for $1 \mathrm{~h}$ at $65^{\circ} \mathrm{C}$. A phenolchloroform automated DNA extraction was performed using the AutoGen 850 system (AutoGen Inc.). DNA was resuspended in $200 \mu \mathrm{l}$ 
of Tris-EDTA buffer with incubation on an orbital shaker for $1 \mathrm{~h}$ at $65^{\circ} \mathrm{C}$, then transferred to $1.5-\mathrm{ml}$ tubes and stored at $-20^{\circ} \mathrm{C}$.

Identification of isolates. Sequences of the ITS 1 and 2 regions of rDNA were obtained by amplification and sequencing with primers ITS6 and ITS4 (Cooke et al. 2000). The polymerase chain reaction (PCR) mix consisted of $1 \times$ DreamTaq buffer, $2 \mathrm{mM} \mathrm{MgCl}_{2}, 0.2 \mathrm{mM}$ $\mathrm{dNTP}, 0.2 \mu \mathrm{M}$ ITS6 and $0.2 \mu \mathrm{M}$ ITS4, bovine serum albumen at $4 \mu \mathrm{g} / \mathrm{ml}, 1 \mathrm{U}$ of DreamTaq polymerase (Thermo Scientific, Waltham, MA), and $1 \mu \mathrm{l}$ of DNA. The thermal cycling program consisted of $95^{\circ} \mathrm{C}$ for $2 \mathrm{~min} ; 35$ cycles of $95^{\circ} \mathrm{C}$ for $1 \mathrm{~min}, 55^{\circ} \mathrm{C}$ for $1 \mathrm{~min}$, and $72^{\circ} \mathrm{C}$ for $1 \mathrm{~min}$; and a final extension at $72^{\circ} \mathrm{C}$ for $10 \mathrm{~min}$. Amplicons were purified by adding $5 \mu \mathrm{l}$ of a mixture of $3 \mathrm{U}$ of exonuclease I and $0.5 \mathrm{U}$ of FastAP thermosensitive alkaline phosphatase (Thermo Scientific), followed by $45 \mathrm{~min}$ at $37^{\circ} \mathrm{C}$, and enzymes were inactivated by incubation at $85^{\circ} \mathrm{C}$ for $10 \mathrm{~min}$. Amplicons were Sanger sequenced in both directions and consensus sequences were obtained for downstream analyses. Sequences were deposited in GenBank under accession codes KU208091 to KU211502 (Rojas et al. in press).

Preprocessing and operational taxonomic unit assignment. The ITS sequences were used to conduct a diversity analysis by grouping the sequences into operational taxonomic units (OTU) using Mothur v1.36 (Schloss et al. 2009), as reported on the Mothur batch file (Supplementary File S1). Sequences were preprocessed, eliminating those with homopolymers of 20 bases or longer. Sequences were reduced to unique sequences and aligned to a reference ITS alignment published by Robideau et al. (2011), allowing for reverse complement to improve and maintain the best match. Sequences were also discarded with an alignment length less than 500 bases. The sequence dataset was further reduced by keeping unique sequences; preclustering was performed to reduce sequencing error, allowing a maximum of three nucleotide differences.

In addition, a preclassification step was conducted using a bootstrap cutoff of 80 of 100 iterations to eliminate OTU outside of the target oomycete taxonomy. Distance was calculated on the resulting sequence dataset using a cutoff of 0.1 , followed by clustering using the furthest neighbor algorithm. The resulting OTU were selected based on a distance cutoff of $97 \%$ similarity, meaning that all sequences in each OTU were within a $3 \%$ distance from other sequences; the OTU designation represents "species-like" designation. In addition, OTU were assigned a taxonomic classification from kingdom to genus, including clades for Pythium and Phytophthora spp., for further analyses and comparisons. A phylotype analysis was conducted using identification based on local blast searches described by Rojas et al. (in press) and using a reference dataset provided by Robideau et al. (2011). The phylotype designation uses the taxonomic assignments based on the database rather than a similarity threshold to bin the samples into groups. The results were collapsed into a phylotype abundance table with corresponding taxonomy assignment (kingdom to species level) for downstream analyses. For interpretation, it should be noted that it is possible to have multiple OTU per phylotype (species designation) due to sequence variation. Resulting OTU and phylotype tables were exported in BIOM files for analysis in $\mathrm{R}$, version 3.2 (R Core Team 2015, Vienna) using the package "phyloseq" (McMurdie and Holmes 2013).

Community and diversity analysis. Estimates for withingroup or field diversity ( $\alpha$ diversity) were calculated using the "vegan" (Oksanen et al. 2013) package in R. These included sample size, richness, Shannon-Wiener index, Simpson index, and evenness (Shannon index divided by natural logarithm of total species per sample) and the data were summarized by state. Fields across states were evaluated for correlation with latitude and longitude using $\alpha$ diversity measures and Spearman correlation. In order to evaluate the community structure, OTU tables were constructed and normalized as relative abundance to determine among-group diversity ( $\beta$ diversity) using Bray-Curtis distances to compare communities pairwise. The resulting dissimilarity matrices were used to assess clustering of the communities by state, and to evaluate communities by field using ordination analysis as principal coordinate analysis (PCoA).
Edaphic and environmental parameters of the sampled fields were acquired based on geographic information system coordinates. Fields without this information were not included in this analyses. Soil chemical and physical properties were obtained from the National Resources Conservation Service soil database (https://www.nrcs.usda.gov/). Ambient temperature (maximum, minimum, and mean) and precipitation (maximum, minimum, and mean) for different time ranges, including yearly and planting season (April, May and June), were obtained from the ParameterElevation Regressions on Independent Slopes Model (PRISM) Climate Group (http://www.prism.oregonstate.edu/). Other parameters such as topology and images for land usage were queried from United States Geological Survey (https://www.usgs.gov/) and the United States Department of Agriculture (USDA) National Agricultural Statistics Service (https://nassgeodata.gmu.edu/ CropScape/), respectively. The information obtained was analyzed in conjunction with community structure and diversity data in $\mathrm{R}$ using the packages vegan and "MASS". The different environmental and edaphic factors were evaluated for community structure and diversity association by using vector fitting in conjunction with the ordination analysis. Environmental factors were plotted as vectors using the "envfit" function from vegan. The environmental and edaphic parameters were corroborated by use of a Mantel test to confirm the correlation with community composition (Ramette 2007). Parameters that showed association with community structure were tested for correlation graphically using ordination and Spearman correlation.

In order to corroborate the effect of environmental variables on oomycete community structure, environmental variables were tested using distance-based redundancy analysis (dbRDA) (Legendre and Anderson 1999). Community data were input as a matrix of BrayCurtis distances and all the explanatory variables were entered into the model and compared with a null model (no explanatory variables) to conduct stepwise selection using the function $\operatorname{ordistep}()$ in vegan (Oksanen et al. 2013) with 10,000 permutations. The model was further refined using variance factor inflation maintaining values $<10$. All data and R scripts used in the analyses shown here are deposited on github (https://github.com/Chilverslab/Rojas_Survey_ Phytopath_2016) and citable (Rojas et al. 2016).

\section{RESULTS}

OTU and phylotype richness per field across states. During the 2-year survey, 125 fields were sampled and 3,418 oomycete isolates were recovered. Although fungi were not the focus of this study, 222 fungal isolates were recovered on the oomycete semiselective medium and the majority consisted of members within the phylum Zygomycota, followed by the phyla Basidiomycota and Ascomycota. The sequences that were identified as fungal species were removed prior to downstream analyses. Based on phylotype analysis conducted with a local blast, 3,242 of the oomycete isolates reside in the genus Pythium, with the remaining isolates corresponding to the following genera: Phytophthora $=142$ isolates, Phytopythium $=31$ isolates, Aphanomyces $=2$ isolates, and, finally, Pythiogeton $=1$ isolate. In the OTU analysis, 2,380 sequences from 2011 and 1,038 sequences from 2012 were combined and analyzed using a 97\% similarity threshold, which resulted in 216 OTU, of which 194 corresponded to Pythium, 13 to Phytopythium, 4 to Phytophthora, 4 to Brevilegnia, and 1 to Aphanomyces; a complete list with species identification is available in Supplementary File S2. The average number of observed OTU ranged from 2.5 to 14 per field across the different states (Table 1). Arkansas in 2011 had the highest diversity, with an average number of 14 OTU per field, whereas South Dakota in 2011 and Iowa in 2012 had the lowest levels of diversity, with observed OTU of 2.5 and 2.8, respectively. The Shannon-Wiener index calculated per field showed that diversity ranged from 0.8 to 2.3 across the different states, where more than $50 \%$ of the fields had values of approximately 1.5 (Table 1 ), thus displaying a moderate 
diversity among fields sampled in the different states. Despite the sampling effort, the recovery of oomycete species in some field and state locations was low, resulting in low species diversity. The Simpson index of diversity favors the dominant or common OTU in the community and uses a scale from 0 (no diversity) to 1 . Approximately $60 \%$ of the fields sampled were approximately 0.5 to 0.8 and, by state, ranged from 0.3 to 0.9 , showing a moderate to high species diversity (Table 1). In addition, there were differences in terms of diversity evenness; more than $50 \%$ of the sites had an evenness above 0.7 , which indicates that a majority of the fields sampled contained close to even distribution of the OTU observed.

Community composition at the state level. Using the taxonomy assignment of the OTU, these were grouped to the oomycete clade level across the states and years sampled (Fig. 1). It was conspicuous that Pythium clades F, B, and I were the most abundant taxa; however, most clades were present to some level in each state. Phytophthora clade 7, which includes Phytophthora sojae, was the most abundant for this genus overall and it was highly abundant in the province of Ontario (Fig. 1). Ontario was the only region that used a soil baiting method, which resulted in a high number of Phytophthora sojae isolates; and, for that reason, it was excluded from most analyses to avoid confounding results. The among-group diversity ( $\beta$ diversity) that describes the compositional dissimilarity between oomycete communities of states was calculated using the Bray-Curtis dissimilarity index. The resulting matrix was analyzed by cluster analysis and plotted as a dendrogram to determine the diversity relationship of each state to another state (Fig. 2A). Geographically adjacent states had similar community structure and, as such, grouped together; for example, Michigan, Indiana, and Illinois grouped together. The analysis did not reveal strong clustering by year of the communities at the state level.

Spatial and temporal effects on community composition at field level. Using diversity per field as response, the effect of latitude and longitude were investigated to corroborate the role of spatial factors on community composition. A significant but weak positive correlation was observed between latitude and diversity $(\rho=0.258, P$ value $=0.0164)($ Fig. $2 B)$, with greater diversity at higher latitudes. This correlation was also observed when comparing latitude using the Simpson diversity index $(\rho=0.239, P$ value $=$ $0.026)$ and number of observed OTU $(\rho=0.189, P$ value $=0.081)$, the latter being nonsignificant. In addition, longitude was examined to determine whether a relationship existed with diversity. It was observed that diversity slightly decreased toward the east (Fig. 2C); this was a weak correlation $(\rho=-0.224, P$ value $=0.037)$ when compared with latitude. Using an analysis of similarity (anosim) permutation test, fields were grouped by latitude and evaluated for community similarity. The results demonstrated significant differences between field community composition at different latitudes $(R$ statistic $=0.103, P$ value $=0.001)$ and more similar composition at similar latitudes. By addressing differences within the field communities in each state using anosim, low differentiation of the communities was found within states, suggesting a similar community composition within state $(R$ statistic $=0.226, P$ value $=0.001)$, but there was significant differentiation among states when state was used as a group. In addition, a temporal effect was also evaluated to determine the contribution of year to differences observed across communities at the field level. Using year as a grouping factor to study dissimilarities of the communities resulted in no differentiation between field communities from 2011 and $2012(R$ statistic $=0.018, P$ value $=$ $0.115)$. In order to corroborate the anosim results and determine the contribution to the variance of the year and state factors using field community composition as a response, a permanova (adonis) test was performed that resulted in significant differences for state and year sampled (Table 2), where $20 \%$ of the community structure variability is explained by state grouping and $1.5 \%$ by year grouping.

Abiotic effects on community composition at the field level. Further investigation of the among-group diversity ( $\beta$ diversity) between fields was examined using a PCoA. The first principal coordinate axis explained $12.1 \%$ and the second principal coordinate axis accounted for $9.4 \%$ of the variability (Fig. 3). The PCoA analysis did not yield clear distance separation of samples by state or year. By incorporating environmental and edaphic factors, it was possible to address which factors caused this gradient or continuum of communities based on their correlation with the

TABLE 1. Oomycete community diversity and evenness by state and year ${ }^{\mathrm{a}}$

\begin{tabular}{|c|c|c|c|c|c|c|c|c|c|}
\hline \multirow[b]{2}{*}{ State, year } & \multicolumn{2}{|c|}{ Number of } & \multicolumn{2}{|c|}{ Observed OTU } & \multicolumn{2}{|c|}{$\begin{array}{c}\text { Shannon-Wiener } \\
\text { index }\end{array}$} & \multicolumn{2}{|c|}{ Simpson index } & \multirow[b]{2}{*}{ Evenness $^{\mathrm{d}}$} \\
\hline & Fields $^{c}$ & Isolates & Mean & SD & Mean & SD & Mean & $\mathrm{SD}$ & \\
\hline Arkansas 2011 & 1 & 320 & 14.00 & ND & 1.19 & ND & 0.60 & ND & 0.45 \\
\hline Arkansas 2012 & 6 & 75 & 7.33 & \pm 4.10 & 1.57 & \pm 0.80 & 0.67 & \pm 0.33 & 0.79 \\
\hline Illinois 2011 & 6 & 243 & 9.00 & \pm 3.20 & 1.66 & \pm 0.40 & 0.73 & \pm 0.12 & 0.76 \\
\hline Illinois 2012 & 6 & 147 & 7.17 & \pm 1.50 & 1.62 & \pm 0.19 & 0.74 & \pm 0.09 & 0.82 \\
\hline Indiana 2011 & 5 & 398 & 10.20 & \pm 1.80 & 1.56 & \pm 0.14 & 0.69 & \pm 0.06 & 0.67 \\
\hline Indiana 2012 & 5 & 33 & 4.00 & \pm 2.30 & 1.08 & \pm 0.72 & 0.55 & \pm 0.33 & 0.78 \\
\hline Iowa 2011 & 9 & 398 & 6.89 & \pm 3.30 & 1.09 & \pm 0.63 & 0.48 & \pm 0.27 & 0.57 \\
\hline Iowa 2012 & 4 & 19 & 2.75 & \pm 1.00 & 0.83 & \pm 0.21 & 0.51 & \pm 0.10 & 0.82 \\
\hline Kansas 2011 & 7 & 213 & 7.43 & \pm 2.80 & 1.36 & \pm 0.55 & 0.61 & \pm 0.26 & 0.68 \\
\hline Kansas 2012 & 6 & 93 & 6.67 & \pm 2.70 & 1.59 & \pm 0.51 & 0.73 & \pm 0.14 & 0.84 \\
\hline Michigan 2011 & 11 & 190 & 5.00 & \pm 3.20 & 1.15 & \pm 0.69 & 0.57 & \pm 0.30 & 0.71 \\
\hline Michigan 2012 & 7 & 134 & 8.29 & \pm 3.70 & 1.75 & \pm 0.49 & 0.76 & \pm 0.13 & 0.83 \\
\hline Minnesota 2011 & 6 & 185 & 10.67 & \pm 6.20 & 1.86 & \pm 0.54 & 0.77 & \pm 0.10 & 0.79 \\
\hline Minnesota 2012 & 6 & 130 & 8.17 & \pm 4.10 & 1.76 & \pm 0.49 & 0.78 & \pm 0.11 & 0.84 \\
\hline N Dakota 2011 & 9 & 210 & 9.56 & \pm 5.60 & 1.78 & \pm 0.63 & 0.76 & \pm 0.16 & 0.79 \\
\hline N Dakota 2012 & 6 & 162 & 10.67 & \pm 2.90 & 1.92 & \pm 0.28 & 0.79 & \pm 0.07 & 0.81 \\
\hline Nebraska 2011 & 4 & 75 & 7.75 & \pm 3.70 & 1.65 & \pm 0.46 & 0.75 & \pm 0.10 & 0.81 \\
\hline Nebraska 2012 & 3 & 49 & 6.67 & \pm 4.00 & 1.64 & \pm 0.61 & 0.76 & \pm 0.13 & 0.86 \\
\hline Ontario 2012 & 1 & 64 & 9.00 & ND & 0.85 & ND & 0.33 & ND & 0.39 \\
\hline S Dakota 2011 & 6 & 24 & 2.50 & \pm 1.40 & 0.75 & \pm 0.49 & 0.47 & \pm 0.25 & 0.82 \\
\hline S Dakota 2012 & 5 & 114 & 13.00 & \pm 3.80 & 2.39 & v0.29 & 0.89 & \pm 0.04 & 0.93 \\
\hline Wisconsin 2011 & 6 & 51 & 4.67 & \pm 2.00 & 1.24 & \pm 0.53 & 0.62 & \pm 0.21 & 0.81 \\
\hline
\end{tabular}


PCoA axes. In total, 37 different environmental and edaphic factors were tested using the envfit function, which fits environmental vectors into the PCoA ordination plot, which resulted in 24 factors correlated with the ordination (Supplementary Table S1). Temperature and precipitation were among the main environmental factors associated with oomycete community structure using different scales such as seasonal parameters, annual averages, or 30-year averages (Table 3). Apart from temperature and precipitation, soil factors of density, water-holding capacity, $\mathrm{pH}$, and $\mathrm{CEC}$ were also significant factors. Latitude, longitude, and precipitation showed the most significant correlation of the evaluated factors related to oomycete community structure (Table 3 ).

Factors significant for envfit analysis were also tested using the Mantel test to corroborate results obtained with the vector-fitting analysis. Most factors were significant for both tests, with the exception of soil bulk density, soil pH, or annual minimum temperature (Table 3). The correlations for significant environmental and edaphic parameters were not above 0.16 ; however, many factors were found to be correlated and contribute to the community composition. Environmental parameters such as temperature and precipitation at different time scales, and edaphic factors such as clay content, CEC, and soil water content, were among the most correlated factors. These correlations were further evaluated using the correlated PCoA axis with the respective linked factor. Factors with long vectors were examined, including seasonal precipitation, seasonal minimum temperature, clay content (percent), and soil bulk density (Fig. 4). Seasonal precipitation and minimum seasonal temperature were evaluated against community composition similarity represented by the correlated PCoA axis. Additionally, samples were visualized with color by latitude. Both seasonal minimum temperature and seasonal precipitation (April to June) showed a negative correlation, indicating that community composition similarity was higher at locations with low precipitation and low temperature average seasonal values (precipitation: $\rho=-0.375$; minimum temperature for the season: $\rho=-0.316$ ).

In regards to latitude and longitude, fields sampled in this study at higher latitudes and located to the west of the sampling area received a lower amount of precipitation and recorded lower temperatures, which affected the community composition. In contrast, samples collected from lower latitudes and to the east received a higher amount of precipitation and experienced higher temperatures, causing a distinct community composition (Fig. 4A and B). The edaphic factors also had an effect on community composition across the samples collected. Clay content and soil bulk density were factors that showed a gradient among the community composition (clay content: $\rho=-0.314$; bulk density: $\rho=$ 0.308 ). In addition, data points were shaded based on water content and related to the two parameters analyzed, clay content and bulk density (Fig. 4C and D). In this case, clay content had a negative correlation with community similarity, where community composition differs along the gradient of soil clay content. Soils with high clay content are different in community structure from soils that have a low clay content, and these differences correlated with water content (Fig. 4C). Soil bulk density had a positive correlation with relatedness among communities, meaning that soils with lower bulk density had communities more similar to each other than communities from high versus low bulk density soils; whereas, soils

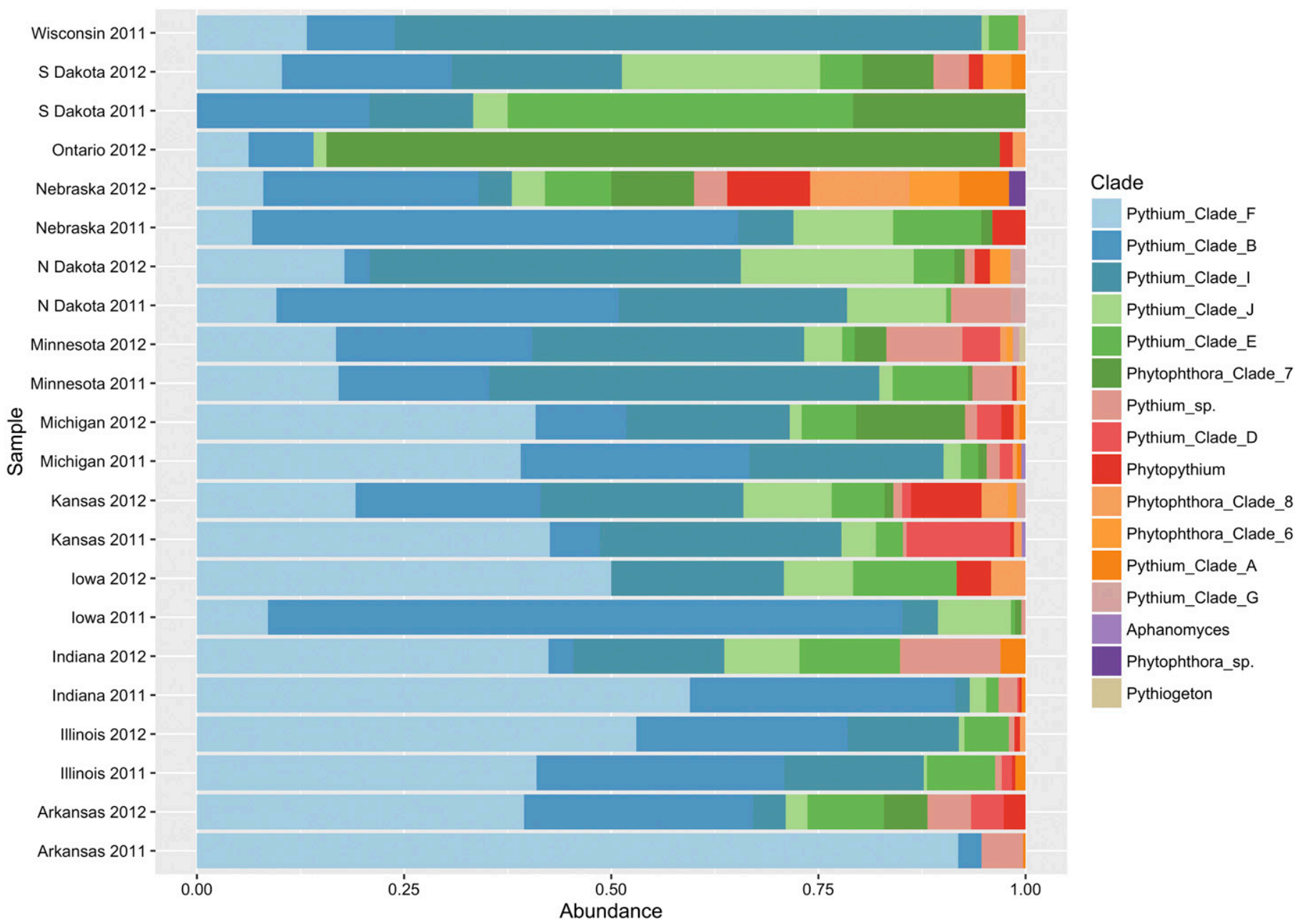

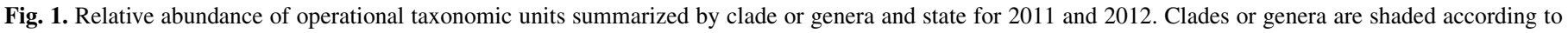
the legend from top to bottom. 
with a higher density tended to have a reduced water content, resulting in a community composition that was more variable, with larger distances between communities (Fig. 4D).

Redundancy analysis on community composition at the field level. By using distance based redundancy analysis (dbRDA), a model selection was conducted by reducing the number of environmental and edaphic variables. The environmental and edaphic variables were redundant and resulted in multicollinearity; thus, using a stepwise variable selection, most variables were rejected. The selection of the variables was retested using variance inflation factors to adjust the model. The selected variables were latitude, longitude, precipitation, and temperature during the season;
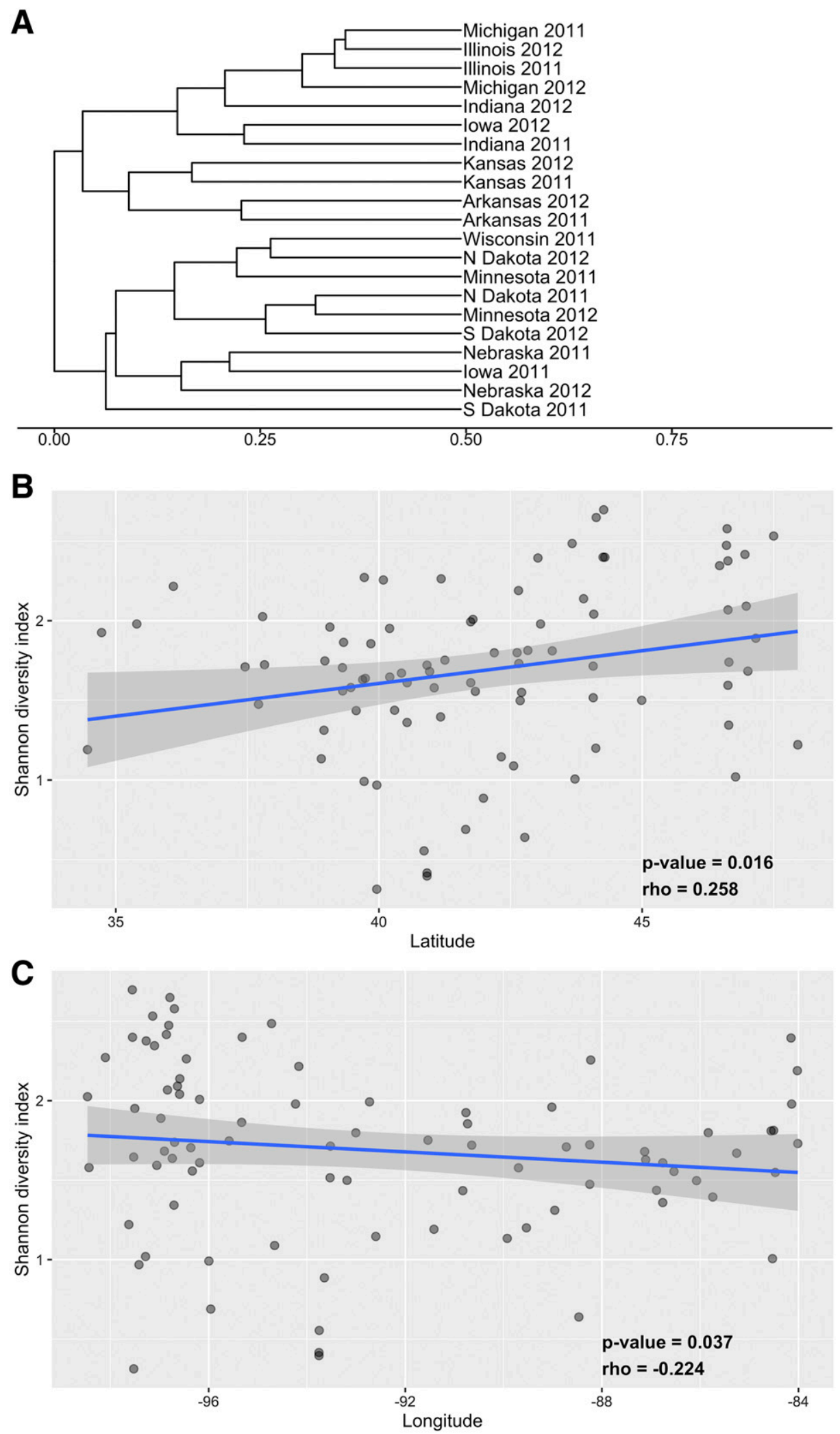

Fig. 2. Oomycete community structure of species recovered from soybean seedling evaluated by A, cluster analysis based on Bray-Curtis distance by state surveyed. Dendrogram was constructed using hierarchical clustering with complete linkage; B, diversity of oomycete communities expressed as Shannon index across the latitudes of the fields sampled; $\mathbf{C}$, diversity of oomycete communities expressed as Shannon index across longitudes of the fields sampled. 
and clay and electrical conductivity (EC). The variables overlapped the variables obtained in the vector-fitting analysis on the PCoA and Mantel test, with the exception of EC (Table 4). The final model resulted in $13 \%$ of the variability explained by the environmental variables. The highest contributions to variance were latitude (4.76\%), longitude $(3.07 \%)$, and seasonal precipitation $(2.47 \%)$, which also contributed the most in the vector fit and Mantel test approach.

Relative abundance and distribution of the top pathogenic species. The abundance of the top eight most frequent pathogenic species was examined by state and it was evident that there were dominant species across multiple state regions. For instance, Pythium sylvaticum was dominant in Michigan, Illinois,

TABLE 2. Evaluation of oomycete community structure ( $\beta$ diversity) differences across states, years, and state-year interaction based on Bray-Curtis distances using adonis

\begin{tabular}{lrccc}
\hline Adonis on Bray-Curtis distances & $\mathrm{df}^{\mathrm{a}}$ & $F$ statistic & $R^{2 \mathrm{~b}}$ & $\operatorname{Pr}(>F)^{\mathrm{b}}$ \\
\hline State & 11 & 2.908 & 0.207 & 0.001 \\
Year & 1 & 2.346 & 0.015 & 0.003 \\
State-Year & 9 & 1.952 & 0.113 & 0.001 \\
Residuals $^{\mathrm{c}}$ & 103 & $\ldots$ & 0.665 & $\ldots$ \\
Total & 124 & $\ldots$ & 1.000 & $\ldots$ \\
\hline
\end{tabular}

${ }^{a}$ Degrees of freedom.

b $R^{2}$ and $P$ value based on 999 permutations.

c Residuals represent the error of the permanova test using distance. and Indiana, whereas states further north were dominated by P. heterothallicum (Fig. 5). These northern states were also dominated by P. ultimum var. ultimum. States toward the south were dominated by $P$. irregulare but the Arkansas community was also dominated by P. sylvaticum. Nebraska, Iowa, and South Dakota communities also contained a considerable percentage of $P$. oopapillum isolates (Fig. 5). To address the trends of individual pathogenic species, abundance of each species was examined in the context of the environmental and edaphic factors previously identified as drivers of community composition (Supplementary Fig. S3). As found in previous studies, some of these parameters could have an effect on their abundance. For instance, $P$. sylvaticum abundance, represented as log-transformed counts of isolates per field, was low with high values of soil $\mathrm{pH}$, $\mathrm{CEC}$, and percent clay content, while its abundance increased with precipitation and temperature (approximately $150 \mathrm{~mm}$ and $12{ }^{\circ} \mathrm{C}$ ). Conversely $P$. heterothallicum abundance increased with increasing $\mathrm{pH}$, percent clay content, and CEC, while the abundance declined with decreasing values of temperature and precipitation.

\section{DISCUSSION}

This study is one of a few that has been conducted to examine oomycete diversity and community composition in an agricultural system at a continental scale. In total, 3,418 oomycete isolates were collected from soybean seedling roots in 125 soybean fields (Rojas et al. in press). The ITS rDNA sequences were analyzed using two

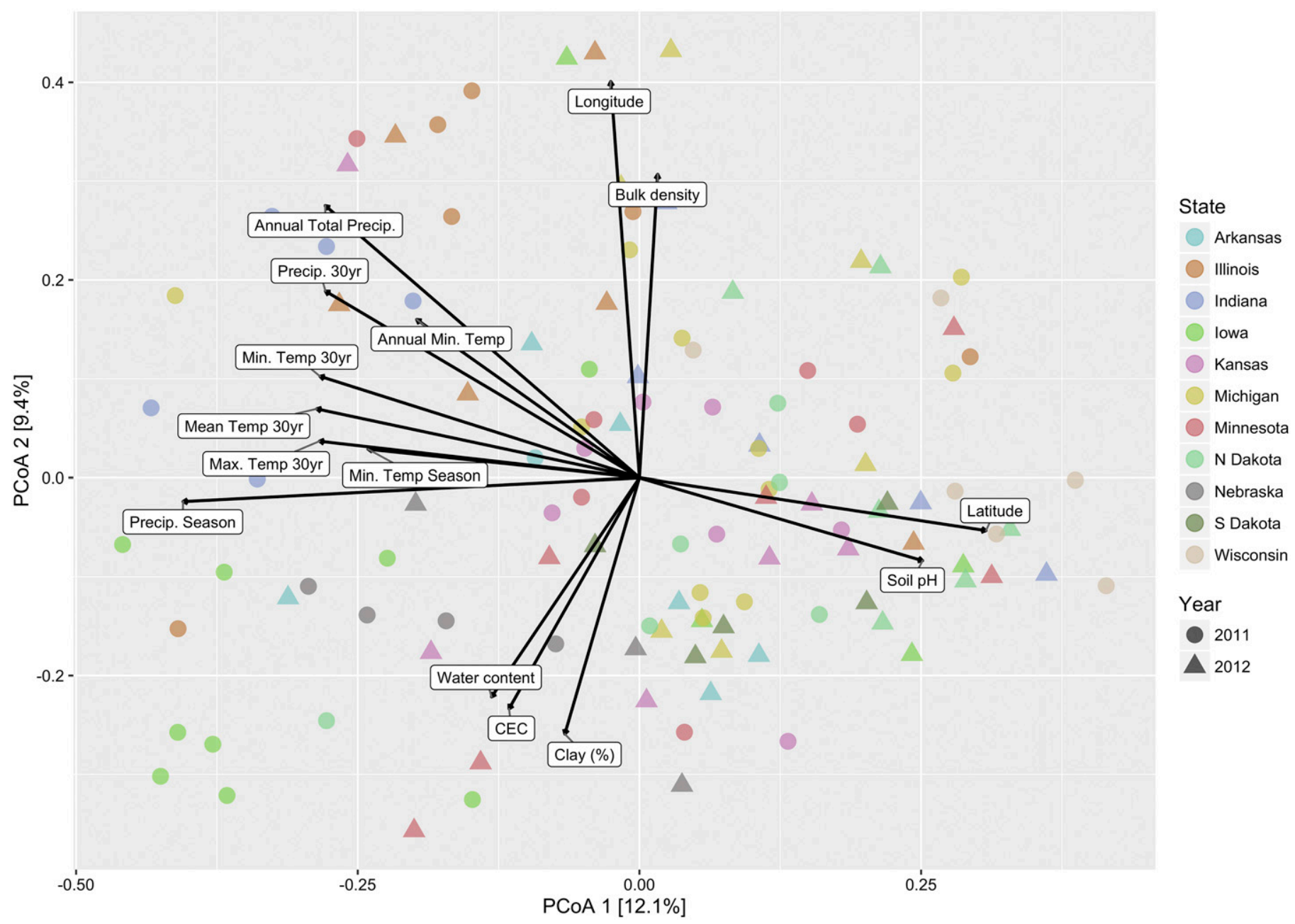

Fig. 3. Principal coordinate analysis (PCoA) of oomycete communities collected from soybean seedlings in the United States based on a Bray-Curtis distance computed from taxon counts. Environmental and edaphic factors are plotted as vectors based on correlations with community distance. Only vectors with significant correlations are represented and the length of the vector represents the strength of the correlation. $\mathrm{CEC}=$ cation exchange capacity; Season corresponds to April, May, and June, when most planting and or sampling was conducted. 
approaches: OTU at $97 \%$ similarity and phylotype at the species level. The OTU approach resulted in 216 OTU, where OTU represent species-like designation; however, intraspecific ITS variability in some species complexes could be higher than the designated species threshold (Schroeder et al. 2013). Therefore, OTU could represent similar species. In the phylotype approach, sequences are assigned based on taxonomy to a local curated database and binned using taxonomic designation. Despite the high number of OTU $(n=216)$ relative to phylotypes $(n=84)$, a similar community composition was observed when compared at the clade level. Both OTU and phylotype analyses have different advantages and disadvantages (Schloss and Westcott 2011). Phylotype is limited by the database, whereas OTU analysis does not require a taxonomic delimitation to bin sequences into groups. OTU were used in this study to obtain the best resolution to investigate the ecological diversity of oomycetes associated with soybean.

Diversity analysis showed that most fields displayed a moderate to high diversity, showing up to 14 OTU, on average, per field. Species abundance varied across the 2 years sampled, which was more conspicuous when looking at OTU grouped at the clade level. In general, most fields had a high evenness, which refers to how evenly represented the different OTU were in each field sampled. The expanse of the survey showed that, at this plant stage, Pythium spp. are widely present on symptomatic seedlings in fields across the predominant soybean production area of North America. The survey revealed that Pythium clades F, B, I, and J were dominant in

TABLE 3. Significance of factors affecting oomycete communities associated with soybean seedlings, based on using envfit function form vegan ${ }^{\mathrm{a}}$

\begin{tabular}{|c|c|c|c|c|c|c|}
\hline \multirow[b]{2}{*}{ Environmental or edaphic parameter } & \multirow[b]{2}{*}{ Axis 1} & \multirow[b]{2}{*}{ Axis 2} & \multicolumn{2}{|c|}{ envfit Test } & \multicolumn{2}{|c|}{ Mantel test } \\
\hline & & & $R^{2}$ & $P$ value & Statistic & $P$ value \\
\hline Precipitation season (mm) & -0.405 & -0.024 & 0.165 & 0.001 & 0.070 & 0.024 \\
\hline Longitude & -0.025 & 0.401 & 0.161 & 0.001 & 0.083 & 0.003 \\
\hline Total precipitation (mm) & -0.279 & 0.275 & 0.154 & 0.001 & 0.117 & 0.006 \\
\hline Precipitation, 30-year average $(\mathrm{mm})$ & -0.279 & 0.189 & 0.113 & 0.002 & 0.103 & 0.006 \\
\hline Latitude & 0.308 & -0.053 & 0.097 & 0.004 & 0.115 & 0.004 \\
\hline Soil bulk density $\left(\mathrm{g} / \mathrm{cm}^{3}\right)$ & 0.016 & 0.307 & 0.094 & 0.004 & 0.023 & 0.275 \\
\hline Minimum temperature, 30 -year average $\left({ }^{\circ} \mathrm{C}\right)$ & -0.284 & 0.102 & 0.091 & 0.006 & 0.085 & 0.022 \\
\hline Mean temperature, 30 -year average $\left({ }^{\circ} \mathrm{C}\right)$ & -0.286 & 0.069 & 0.087 & 0.007 & 0.122 & 0.001 \\
\hline Maximum temperature, 30 -year average $\left({ }^{\circ} \mathrm{C}\right)$ & -0.284 & 0.037 & 0.082 & 0.009 & 0.153 & 0.001 \\
\hline Clay content $(\%)$ & -0.066 & -0.259 & 0.072 & 0.019 & 0.151 & 0.003 \\
\hline Soil pH & 0.251 & -0.084 & 0.070 & 0.022 & 0.044 & 0.106 \\
\hline Cation exchange capacity (meq/100 g) & -0.116 & -0.234 & 0.068 & 0.017 & 0.080 & 0.033 \\
\hline Water content & -0.131 & -0.222 & 0.066 & 0.022 & 0.143 & 0.003 \\
\hline Minimum temperature $\left({ }^{\circ} \mathrm{C}\right)$ & -0.198 & 0.160 & 0.065 & 0.018 & 0.068 & 0.073 \\
\hline Minimum temperature season $\left({ }^{\circ} \mathrm{C}\right)$ & -0.241 & 0.029 & 0.059 & 0.031 & 0.106 & 0.006 \\
\hline
\end{tabular}

a Axis 1 and Axis 2 explain 12.1 and $9.4 \%$, respectively, of the variability between communities.
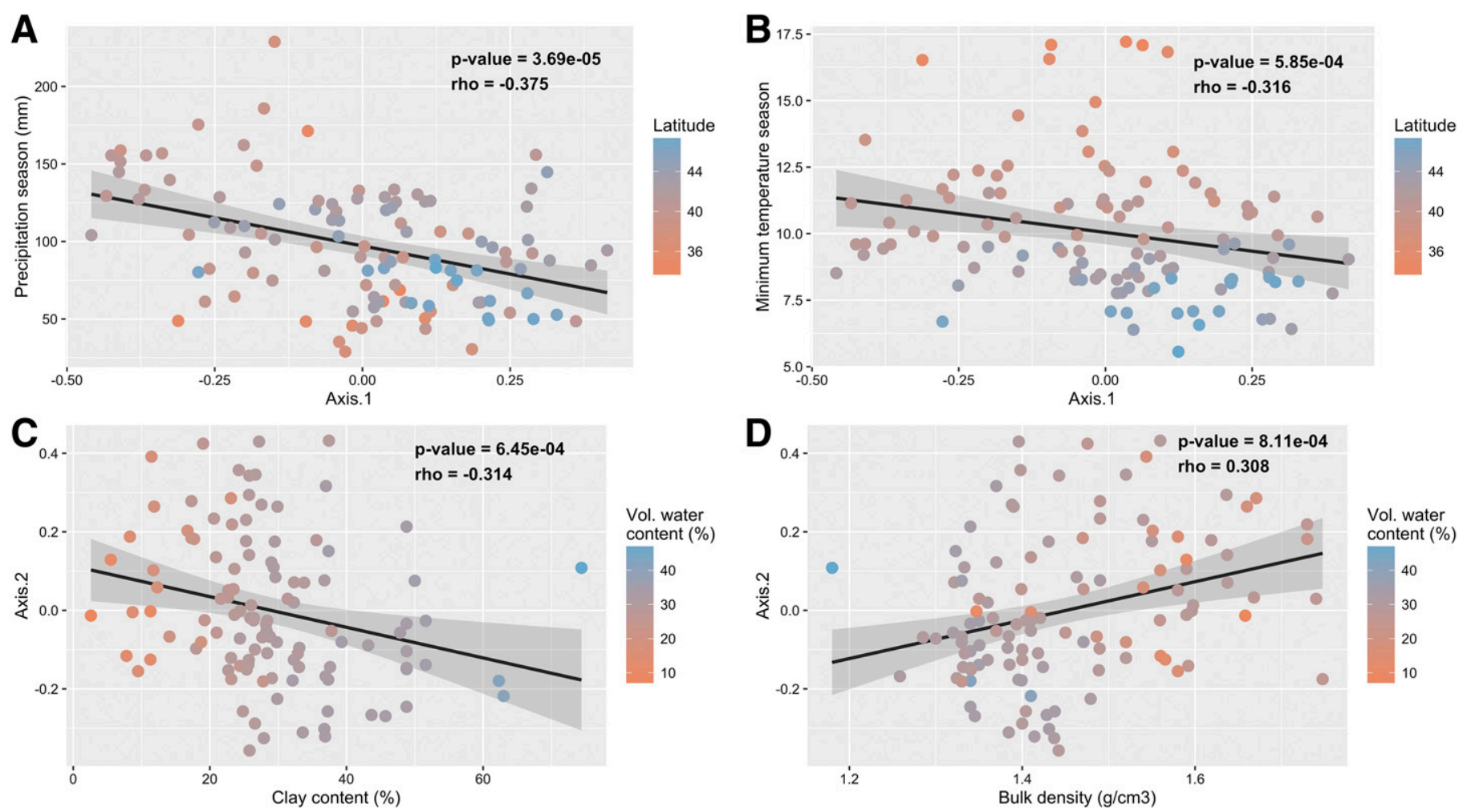

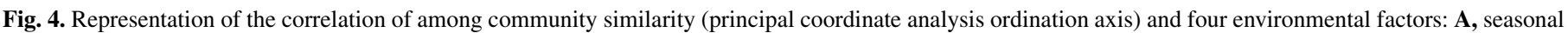

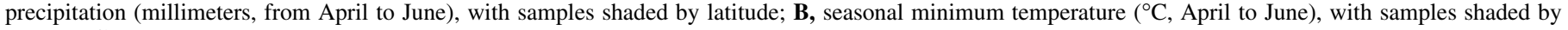

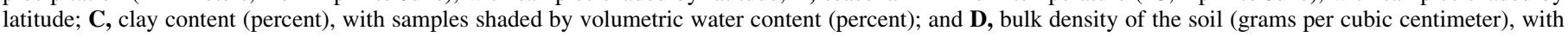

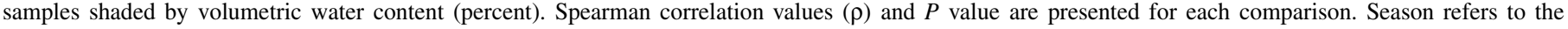
planting or sampling period, which ranged from April to June. 
most states and contributed to at least $50 \%$ of the community composition. These clades also contain most of the plant-pathogenic species (Lévesque and De Cock 2004). The remaining percent of the communities were partitioned into the Pythium clades A, D, E, and G; Phytophthora clades 6, 7, and 8; and the genera Phytopythium, Aphanomyces, and Pythiogeton. This study corroborates state-level studies that found Pythium spp. abundantly present in soybean fields (Ellis et al. 2012; Murillo-Williams and Pedersen 2008; Rizvi and Yang 1996; Zitnick-Anderson and Nelson 2015).

The composition of the communities associated with soybean seedlings was significantly different by state but states geographically close in proximity exhibited similarity based on clustering. This finding suggests an effect of geographical location on oomycete community composition. Therefore, field community diversity was evaluated as response to latitude and longitude. A diversity gradient was observed by latitude, with diversity increasing as latitude increased, but the linear model did not find a significant correlation for longitude. The result was also supported by the use of anosim, a distribution-free method of multivariate analysis, with the anosim test finding a significant effect by latitude $(R$ statistic $=0.103, P$ value $=0.001)$ but not longitude $(R$ statistic $=$ $0.040, P$ value $=0.099)$. The present study is limited to regions where soybean crops are grown; however, this spatial effect is concordant with other systems, especially in fungal groups (Tedersoo et al. 2014). Ectomycorrhizal fungi reached the highest diversity at midlatitudes of 40 to $60^{\circ}$, whereas other fungal groups such as Ascomycota peaked at latitudes associated with tropical

TABLE 4. Relationships of the predictor variables determined by distancebased redundancy analysis to the oomycete community composition from soybean seedlings ${ }^{\mathrm{a}}$

\begin{tabular}{lccr}
\hline Explanatory variables & Variance & $F$ & $\operatorname{Pr}(>F)$ \\
\hline Latitude & 0.048 & 5.083 & $<0.001$ \\
Longitude & 0.031 & 3.667 & $<0.001$ \\
Season precipitation & 0.025 & 3.105 & $<0.001$ \\
Season minimum temperature & 0.011 & 1.573 & 0.033 \\
Clay (\%) & 0.009 & 1.374 & 0.094 \\
Electrical conductivity & 0.007 & 1.490 & 0.051 \\
\hline
\end{tabular}

a The 34 environmental and edaphic variables were tested against a null model and selected using stepwise selection and variance inflation factors. regions. It has been suggested that oomycetes may have a higher diversity in tropical areas; however, this is based on the description of new genera in these areas (Nigrelli and Thines 2013) and requires additional investigation.

The effect of spatial distribution on the differentiation of field communities among states was further evaluated using the permanova (adonis) analysis, which is a nonparametric method to determine sample grouping. The differences among community composition resulted in $20 \%$ of the variability explained by state. With respect to temporal variation or the effect of season on community composition, only $1.5 \%$ of variability was explained by year in the permanova test, despite environmental conditions that varied between 2011 and 2012, and the use of two semiselective medium in 2012. The anosim resulted in nonsignificant differences between the years. However, looking at composition by year and state explained $11.1 \%$ of the variability, suggesting that community composition is affected at a regional scale across the seasons sampled rather than by sampling year. These results suggest that there is a spatial component that contributes to community composition, which is stronger than a seasonal sampling component.

The ordination method of PCoA, which uses differences amongfield communities ( $\beta$ diversity), revealed that 12 and $9.4 \%$ variability is explained not by the presence of different OTU but from the differences in abundance between states and years, respectively. Environmental and edaphic factors were explored to determine the effect on community composition. Of 34 environmental and edaphic parameters tested, 15 showed significant correlations with the among-group oomycete diversity at the field level. A vector-fitting approach and Mantel test were conducted to confirm those factors that could explain the variance across community composition. Of the environmental parameters evaluated, temperature and precipitation were correlated with community composition. With respect to edaphic factors, soil bulk density, clay content, $\mathrm{pH}$, and CEC were factors that also correlated with community composition. As expected, multiple factors contributed to explain the variability of community composition across fields. These contributions were small but significant, which is common in ecology studies because many variables may contribute to the abundance and distribution of species. A further delimitation of the environmental and edaphic variables as predictors of community composition was done using redundancy analyses. The goal was to

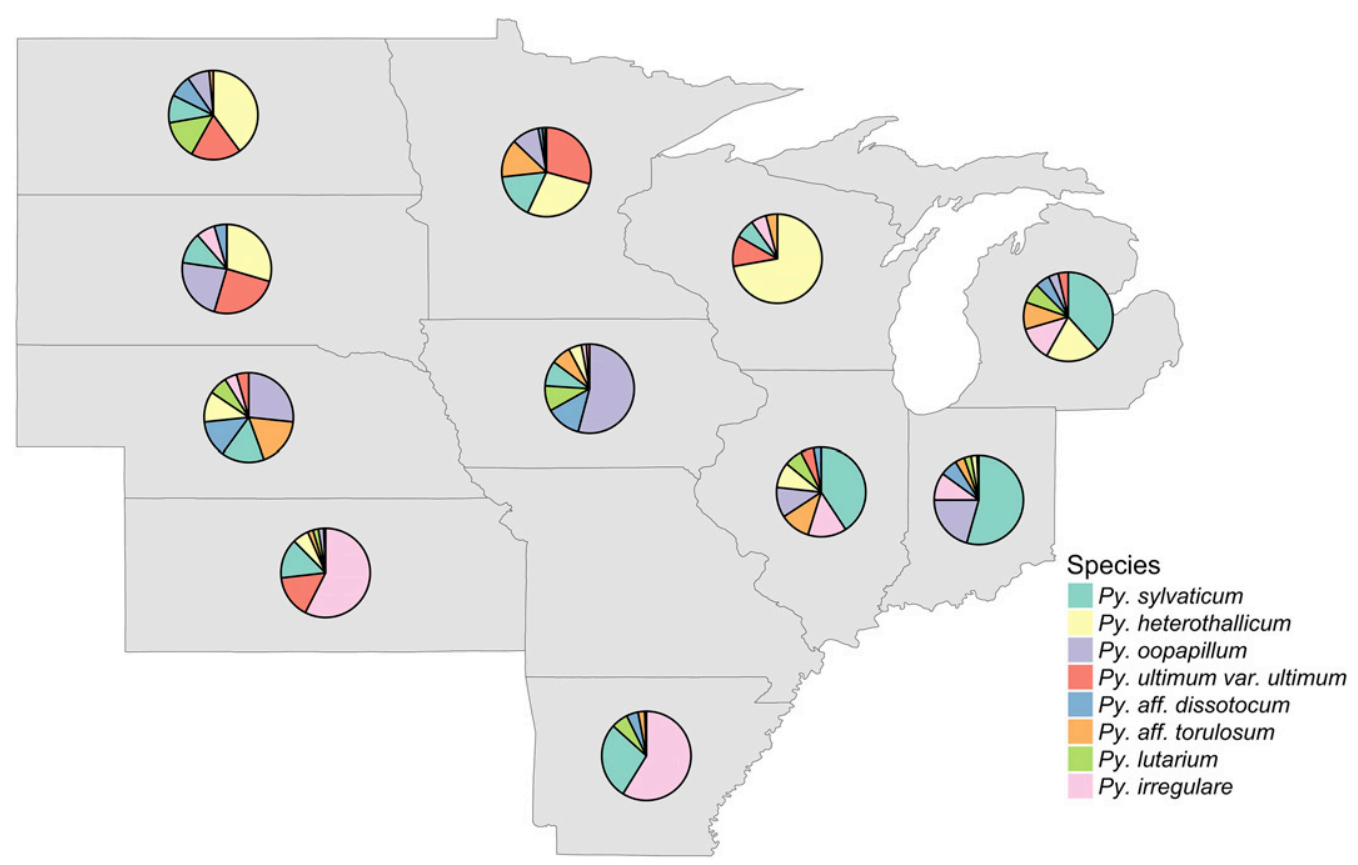

Fig. 5. Distribution and abundance of the top eight pathogenic oomycete species across the states sampled in 2011 and 2012. 
systematically reduce the variables, reducing collinear factors that explain the community observed and also the contribution of each factor. This method resulted in corroboration of parameters previously detected by vector-fitting and Mantel tests, resulting in latitude, longitude, seasonal temperature, seasonal precipitation, and clay content as variables that explained the variance observed in community composition. This supports the idea of geographical location and local environment playing a role in the oomycete community composition.

The environmental and edaphic factors identified in this study relate to the biology and ecology of these organisms; for example, moisture as affected by precipitation and soil water-holding properties is a requirement for oospore germination, sporangia formation, and zoospore motility (Martin and Loper 1999). In addition, nutrient availability, like ions, has been demonstrated to have differential effects on particular Pythium spp. For example, chlorine availability can decrease inoculum density of $P$. ultimum while promoting soil colonization by $P$. oligandrum (Martin and Hancock 1986). Among the different edaphic factors evaluated, EC, CEC, and soil $\mathrm{pH}$ were associated with the oomycete community present. For instance, $P$. heterothallicum increased in abundance at approximately pH 7 to 8 and a CEC of 30 to 40 meq per $100 \mathrm{~g}$, whereas $P$. sylvaticum abundance decreased under the same conditions (Fig. 5). It suggests that high values of CEC are correlated with high diversity, because some dominant species will decrease their propagule density, favoring other species (Broders et al. 2009; Martin and Loper 1999).

Another factor to consider is the temporal component of sampling, because some species might become active under different environmental conditions or plant stages. Surprisingly, Phytophthora spp. were recovered in low abundance despite the use of a semiselective medium in 2012 that contained hymexazol. Hymexazol is added to semiselective medium to reduce Pythium spp. recovery while increasing Phytophthora spp. recovery (Jeffers 1986; Tsao and Guy 1977). Phytophthora sojae, recognized as an aggressive pathogen of soybean, was found in 8 of 11 states surveyed but was recovered at low frequencies. The low abundance of Phytophthora sojae was somewhat surprising because it was found to be widely present in fields across the United States in a survey which utilized a baiting method from soil samples (Dorrance et al. 2016), and in samples from Ontario in the present study, which also used a baiting method. Therefore, it suggests that this species might have a low propagule density in the soil, and these only become active under specific conditions such as soil saturation for extended periods of time. The microbial seed bank present in the soil is not represented in the current study; rather, it is a subsample of the active community at the time of sampling. It has been widely discussed how dormant spores and other long-term survival structures are present in the soil and germinate under specific conditions such as soil saturation or cool or warm temperature, depending on the species, or when biologically important elements, including plant exudates and volatiles, are present (Lennon and Jones 2011).

Previous studies have demonstrated that, despite the abundance of Pythium spp. in natural systems, the community structure of this genus and other oomycetes can be affected by biotic and abiotic factors (Arcate et al. 2006; Coffua et al. 2016; Nelson and Karp 2013). Overall, we found evidence that spatial effects contribute mainly to community composition at the field level across different states; however, the autocorrelation of spatial effects with environmental data can also contribute to community composition. In fact, temperature and precipitation were also designated as variables that contributed to explain the variance observed across field community composition. Therefore, local conditions seem to correlate with the community composition at each field within each state, where precipitation and temperature at planting will determine the species actively germinating and infecting soybean seedlings. It is important to clarify that the variables correlated in the present study predict $16 \%$ of the variability, which means that there are more parameters involved affecting the community structure of oomycetes in soybean fields. These factors could include sampling stochasticity and ecological stochasticity in community composition, seed treatments, host genetics, and even agricultural practices; hence, some species could be promoted by particular conditions at the field scale. In addition, community composition at the state scale was also affected by fluctuation from year to year. For instance, 2011 had more frequent precipitation with mild temperatures, whereas 2012 had dry conditions and higher temperatures at the state level (Supplementary Fig. S2). These fluctuations were not evident at a continental scale between seasons but, rather, at the state level between seasons, as evaluated with anosim and adonis. The regional climate from year to year could promote or suppress the germination and proliferation of different oomycete species, affecting the geographical niches. For example, it was noted that Pythium oopapillum was abundant under the high precipitation and cool temperatures experienced at the start of the 2011 growing season but was far less abundant in the warmer, drier season of 2012. The effect of temperature on virulence and possible abundance of this species was reflected in a seed rot assay, where $P$. oopapillum was far more virulent at 13 than at $20^{\circ} \mathrm{C}$ (Rojas et al. in press).

Changes in agricultural practices over the last few decades such as reduced rotations, early planting, and minimum- or no-till coupled with changes in precipitation have promoted conditions that favor oomycete seedling disease (Koenning and Wrather 2010; Melillo et al. 2014; Workneh et al. 1999; Wrather and Koenning 2009). To this end, the primary goal of this research was to use an ecology approach to address the diversity of oomycetes associated with soybean seedling diseases and characterize the effect of environment and edaphic factors on their distribution and abundance. The results indicate that communities were dominated by Pythium clades F, B, and I, which contain a large percentage of the plant-pathogenic species (Lévesque and De Cock 2004). The differences in abundance of the OTU across different states were correlated initially with a spatial effect, dictated mainly by latitude and in lower contribution by longitude. As a result of this, environmental factors intrinsically related to geographical location such as temperature and precipitation contributed to oomycete community composition at the field scale. These conditions demonstrated an effect on the abundance of the top pathogenic species, suggesting an effect on the overall community composition and assembly at each field. This information provides a basis to understand the composition of oomycete communities in soybean fields; however, further research is needed to characterize other factors that contribute to the community assembly, including agricultural practices. It will be necessary to conduct controlled experiments to refine the effect of these environmental conditions on the community and the species at the field scale. Current efforts are underway to use amplicon-based community analysis to characterize the communities present in the soil of these fields. The use of amplicon and metagenomics approaches will allow for additional understanding of the diversity of the microbial seed bank present and the ecology of these ecosystems (Coffua et al. 2016; Lindahl et al. 2013; Sapkota and Nicolaisen 2015; Song et al. 2015). The information provided on community composition will help us develop models to reduce and manage the abundance of species as related to disease on soybean and possibly other crops. Future studies should address the influence of cultivar genotype, crop rotation, management inputs, soil fertility practices, and tillage practices on oomycete communities and root diseases.

\section{ACKNOWLEDGMENTS}

This project was supported by Agriculture and Food Research Initiative Competitive Grant number 2011-68004-30104 from the USDA National Institute of Food and Agriculture and Project GREEEN GR11-081. The project was also supported, in part, by the United Soybean Board and North Central Soybean Research Programs. Ontario participation was supported by the Grain Farmers of Ontario who obtained funding, in part, through Growing Forward 2 (GF2), a federal-provincial-territorial initiative. The Agricultural Adaptation Council assists in the delivery of GF2 in Ontario. We thank the following personnel who made this project possible: 
T. Welacky (Ontario), T. Anderson (Ontario), C. Van Herk (Ontario), G. Kotulak (Ontario), G. Stasko (Ontario), A. Steger (Arkansas), R. Holland (Arkansas), K. Urrea (Arkansas), N. Anderson (Indiana), J. Ravellette (Indiana), R. Matthiesen (Iowa), V. Silva (Iowa), D. Pedersen (Illinois), U. Reuter-Carlson (Illinois), J. O'Mara (Kansas), B. Grabow (Kansas), B. McKinzie (Kansas), C. Floyd (Minnesota), and C. Groves (Wisconsin); F. Martin for helpful discussion; and two anonymous reviewers who provided insightful comments on this manuscript.

\section{LITERATURE CITED}

American Soybean Association. 2015. Soy Stats 2015: A Reference Guide to Important Soybean Facts \& Figures. Online publication. http://soystats.com/

Arcate, J. M., Karp, M. A., and Nelson, E. B. 2006. Diversity of peronosporomycete (oomycete) communities associated with the rhizosphere of different plant species. Microb. Ecol. 51:36-50.

Broders, K. D., Lipps, P. E., Paul, P. A., and Dorrance, A. E. 2007. Characterization of Pythium spp. associated with corn and soybean seed and seedling disease in Ohio. Plant Dis. 51:727-735.

Broders, K. D., Wallhead, M. W., Austin, G. D., Lipps, P. E., Paul, P. A., Mullen, R. W., and Dorrance, A. E. 2009. Association of soil chemical and physical properties with Pythium species diversity, community composition, and disease incidence. Phytopathology 99:957-967.

Coffua, L. S., Veterano, S. T., Clipman, S. J., Mena-Ali, J. I., and Blair, J. E. 2016. Characterization of Pythium spp. associated with asymptomatic soybean in southeastern Pennsylvania. Plant Dis. 100:1870-1879.

Cooke, D. E., Drenth, A., Duncan, J. M., Wagels, G., and Brasier, C. M. 2000. A molecular phylogeny of Phytophthora and related oomycetes. Fungal Genet. Biol. 30:17-32.

Crocker, E. V., Karp, M. A., and Nelson, E. B. 2015. Virulence of oomycete pathogens from Phragmites australis-invaded and noninvaded soils to seedlings of wetland plant species. Ecol. Evol. 5:2127-2139.

Dorrance, A. E., Berry, S. A., Anderson, T. R., and Meharg, C. 2008. Isolation, storage, pathotype characterization, and evaluation of resistance for Phytophthora sojae in soybean. Online publication. Plant Health Prog. doi: 10.1094/PHP-2008-0118-01-DG

Dorrance, A. E., Kurle, J. E., Robertson, A. E., Bradley, C., Giesler, L., Wise, K. A., and Concibido, V. C. 2016. Pathotype diversity of Phytophthora sojae in eleven states in the United States. Plant Dis. 100:1429-1437.

Dorrance, A. E., McClure, S. A., and deSilva, A. 2003. Pathogenic diversity of Phytophthora sojae in Ohio soybean fields. Plant Dis. 87:139-146.

Ellis, M. L., Paul, P. A., Dorrance, A. E., and Broders, K. D. 2012. Two new species of Pythium, P. schmitthenneri and P. selbyi pathogens of corn and soybean in Ohio. Mycologia 104:477-487.

Erwin, D. C., and Ribeiro, O. K. 1996. Phytophthora Diseases Worldwide. American Phytopathological Society Press, St. Paul, MN.

Hansen, E. M., Reeser, P. W., and Sutton, W. 2012. Phytophthora beyond agriculture. Annu. Rev. Phytopathol. 50:359-378.

Jeffers, S. N. 1986. Comparison of two media selective for Phytophthora and Pythium species. Plant Dis. 70:1038-1043.

Jiang, Y. N., Haudenshield, J. S., and Hartman, G. L. 2012. Characterization of Pythium spp. from soil samples in Illinois. Can. J. Plant Pathol. 34:448-454.

Knaus, B. J., Fieland, V. J., Graham, K. A., and Grünwald, N. J. 2015. Diversity of foliar Phytophthora species on Rhododendron in Oregon nurseries. Plant Dis. 99:1326-1332.

Koenning, S. R., and Wrather, J. A. 2010. Suppression of soybean yield potential in the continental United States by plant diseases from 2006 to 2009. Online publication. Plant Health Prog. doi:10.1094/PHP-20101122-01-RS

Legendre, P., and Anderson, M. J. 1999. Distance-based redundancy analysis: Testing multispecies responses in multifactorial ecological experiments. Ecol. Monogr. 69:1-24.

Lennon, J. T., and Jones, S. E. 2011. Microbial seed banks: The ecological and evolutionary implications of dormancy. Nat. Rev. Microbiol. 9:119-130.

Lévesque, C. A. 2011. Fifty years of oomycetes-From consolidation to evolutionary and genomic exploration. Fungal Divers. 50:35-46.

Lévesque, C. A., and De Cock, A. W. A. M. 2004. Molecular phylogeny and taxonomy of the genus Pythium. Mycol. Res. 108:1363-1383.

Lindahl, B. D., Nilsson, R. H., Tedersoo, L., Abarenkov, K., Carlsen, T., Kjøller, R., Kõljalg, U., Pennanen, T., Rosendahl, S., Stenlid, J., and Kauserud, H. 2013. Fungal community analysis by high-throughput sequencing of amplified markers-A user's guide. New Phytol. 199: 288-299.

Marchand, G., Chen, Y., Berhane, N. A., Wei, L., Lévesque, C. A., and Xue, A. G. 2014. Identification of Pythium spp. from the rhizosphere of soybeans in Ontario, Canada. Can. J. Plant Pathol. 36:246-251.

Martin, F., and Hancock, J. 1986. Association of chemical and biological factors in soils suppressive to Pythium ultimum. Phytopathology 76:1221-1231.
Martin, F. N., and Loper, J. E. 1999. Soilborne plant diseases caused by Pythium spp.: Ecology, epidemiology, and prospects for biological control. Crit. Rev. Plant Sci. 18:111-181.

McMurdie, P. J., and Holmes, S. 2013. phyloseq: An R package for reproducible interactive analysis and graphics of microbiome census data. PLoS One 8:e61217.

Melillo, J. M., Richmond, T., and Yohe, G. W. 2014. Climate change impacts in the United States: The third national climate assessment. US Global change research program 841.

Murillo-Williams, A., and Pedersen, P. 2008. Early Incidence of Soybean Seedling Pathogens in Iowa. Agron. J. 100:1481-1487.

Nagel, J. H., Slippers, B., Wingfield, M. J., and Gryzenhout, M. 2015. Multiple Phytophthora species associated with a single riparian ecosystem in South Africa. Mycologia 107:915-925.

Nelson, E. B., and Karp, M. A. 2013. Soil pathogen communities associated with native and non-native Phragmites australis populations in freshwater wetlands. Ecol. Evol. 3:5254-5267.

Nigrelli, L., and Thines, M. 2013. Tropical oomycetes in the German Bight-Climate warming or overlooked diversity? Fungal Ecol. 6:152-160.

Oksanen, J., Blanchet, F. G., Kindt, R., Legendre, P., Minchin, P. R., Simpson, G. L., Solymos, P., Stevens, M. H. H., and Wagner, H. 2013. vegan: Community ecology package. $\mathrm{R}$ package version $2.0-7$. Online publication. http://vegan.r-forge.r-project.org/

Parke, J., Knaus, B. J., Fieland, V. J., Lewis, C., and Grunwald, N. J. 2014. Phytophthora community structure analyses in Oregon nurseries inform systems approaches to disease management. Phytopathology 104:1052-1062.

Ramette, A. 2007. Multivariate analyses in microbial ecology. FEMS Microbiol. Ecol. 62:142-160.

Rizvi, S. S. A., and Yang, X. B. 1996. Fungi associated with soybean seedling disease in Iowa. Plant Dis. 80:57-60.

Robideau, G., De Cock, A. W. A. M., Coffey, M. D., Voglmayr, H., Brouwer, H., Bala, K., Chitty, D. W., Désaulniers, N., Eggertson, Q. A., Gachon, C. M. M., Hu, C.-H., Küpper, F. C., Rintoul, T. L., Sarhan, E., Verstappen, E. C. P., Zhang, Y., Bonants, P. J. M., Ristaino, J. B., and Lévesque, C. A. 2011. DNA barcoding of oomycetes with cytochrome c oxidase subunit I and internal transcribed spacer. Mol. Ecol. Resour. 11:1002-1011.

Rojas, J. A., Jacobs, J., Napieralski, S., Karaj, B., Bradley, C. A., Chase, T., Esker, P., Smith, D., Giesler, L., Jardine, D., Malvick, D., Markell, S., Nelson, B., Robertson, A., Rupe, J., Sweets, L., Tenuta, A., Wise, K., and Chilvers, M. 2016. Oomycete species associated with soybean seedlings in North America. Online publication. Zenodo. doi:10.5281/zenodo.50107

Rojas, J. A., Jacobs, J. L., Napieralski, S., Bradley, C. A., Chase, T., Esker, P. D., Giesler, L., Jardine, D., Nelson, B. D., Malvick, D., Markell, S., Robertson, A. E., Rupe, J. C., Sweets, L., Wise, K., and Chilvers, M. I. Oomycete species associated with soybean seedlings in North America Part I: Identification and pathogenicity characterization. Phytopathology 107:280-292.

Sapkota, R., and Nicolaisen, M. 2015. An improved high throughput sequencing method for studying oomycete communities. J. Microbiol. Methods 110:33-39.

Schloss, P. D., and Westcott, S. L. 2011. Assessing and improving methods used in Operational Taxonomic Unit-based approaches for 16S rRNA gene sequence analysis. Appl. Environ. Microbiol. 77:3219-3226.

Schloss, P. D., Westcott, S. L., Ryabin, T., Hall, J. R., Hartmann, M., Hollister, E. B., Lesniewski, R. A., Oakley, B. B., Parks, D. H., and Robinson, C. J. 2009. Introducing Mothur: Open-source, platform-independent, communitysupported software for describing and comparing microbial communities. Appl. Environ. Microbiol. 75:7537-7541.

Schroeder, K. L., Martin, F. N., De Cock, A. W. A. M., Lévesque, C. A., Spies, C. F. J., Okubara, P. A., and Paulitz, T. C. 2013. Molecular detection and quantification of Pythium species: Evolving taxonomy, new tools, and challenges. Plant Dis. 97:4-20.

Scibetta, S., Schena, L., Chimento, A., Cacciola, S. O., and Cooke, D. E. L. 2012. A molecular method to assess Phytophthora diversity in environmental samples. J. Microbiol. Methods 88:356-368.

Song, Z., Schlatter, D., Kennedy, P., Kinkel, L. L., Kistler, H. C., Nguyen, N., and Bates, S. T. 2015. Effort versus reward: Preparing samples for fungal community characterization in high-throughput sequencing surveys of soils. PLoS One 10:e127234.

Tedersoo, L., Bahram, M., Põlme, S., Kõljalg, U., Yorou, N. S., Wijesundera, R., Villarreal Ruiz, L., Vasco-Palacios, A. M., Thu, P. Q., Suija, A., Smith, M. E., Sharp, C., Saluveer, E., Saitta, A., Rosas, M., Riit, T., Ratkowsky, D., Pritsch, K., Põldmaa, K., Piepenbring, M., Phosri, C., Peterson, M., Parts, K., Paertel, K., Otsing, E., Nouhra, E., Njouonkou, A. L., Nilsson, R. H., Morgado, L. N., Mayor, J., May, T. W., Majuakim, L., Lodge, D. J., Lee, S. S., Larsson, K.-H., Kohout, P., Hosaka, K., Hiiesalu, I., Henkel, T. W., Harend, H., Guo, L.-d., Greslebin, A., Grelet, G., Geml, J., Gates, G., Dunstan, W., Dunk, C., Drenkhan, R., Dearnaley, J., De Kesel, A., Dang, T., Chen, X., Buegger, F., Brearley, F. Q., Bonito, G., Anslan, S., Abell, S., and 
Abarenkov, K. 2014. Global diversity and geography of soil fungi. Science 346:Issue 6213. doi:10.1126/science.1256688

Tsao, P. H., and Guy, S. O. 1977. Inhibition of Mortierella and Pythium in a Phytophthora-isolation medium containing hymexazol. Phytopathology 67: 796-801.

Tyler, B. M. 2007. Phytophthora sojae: Root rot pathogen of soybean and model oomycete. Mol. Plant Pathol. 8:1-8.

van der Plaats-Niterink, A. J. 1981. Monograph of the Genus Pythium. Studies in Mycology. Centraalbureau voor Schimmelcultures, Baarn, The Netherlands.

Workneh, F., Tylka, G. L., Yang, X. B., Faghihi, J., and Ferris, J. M. 1999. Regional assessment of soybean brown stem rot, Phytophthora sojae, and Heterodera glycines using area-frame sampling: Prevalence and effects of tillage. Phytopathology 89:204-211.
Wrather, A., and Koenning, S. 2000. Effects of diseases on soybean yields in the United States 1996 to 2007. Online publication. Plant Health Prog. doi: 10.1094/PHP-2009-0401-01-RS

Zhang, B. Q., Chen, W. D., and Yang, X. B. 1998. Occurrence of Pythium species in long-term maize and soybean monoculture and maize/soybean rotation. Mycol. Res. 102:1450-1452.

Zhang, B. Q., and Yang, X. B. 2000. Pathogenicity of Pythium populations from Corn-Soybean rotation fields. Plant Dis. 84:94-99.

Zitnick-Anderson, K. K., Norland, J. E., del Rio, L., Fortuna, A. M., and Nelson, B. 2014. Soil properties associated with the presence of Pythium communities in soybean roots. (Abstr.) Phytopathology 104:S3-138.

Zitnick-Anderson, K. K., and Nelson, B. D. 2015. Identification and pathogenicity of Pythium on soybean in North Dakota. Plant Dis. 99: $31-38$ 